\title{
Bond strength of a calcium silicate- based sealer tested in bulk or with different main core materials
}

Emre NAGAS ${ }^{(a)}$

Zafer CEHRELI(b)

Mehmet Ozgur UYANIK(a)

Veli DURMAZ(a)

\footnotetext{
(a) Department of Endodontics, Faculty of Dentistry, Hacettepe University, Ankara, Turkey.

(b) Department of Pediatric Dentistry, Faculty of Dentistry, Hacettepe University, Ankara, Turkey.
}

Declaration of Interests: The authors certify that they have no commercial or associative interest that represents a conflict of interest in connection with the manuscript.

Corresponding Author:

Emre Nagas

E-mail: emrenagas@yahoo.com

DOI: 10.1590/1807-3107BOR-2014.vol28.0046

Submitted: Dec 12, 2013

Accepted for publication: Jun 01, 2014

Last revision: Aug 18, 2014

\begin{abstract}
The aim of this study was to evaluate the influence of a calcium silicate-based sealer (iRoot SP), with or without a core material, on bond strength to radicular dentin, in comparison with various contemporary root filling systems. Root canals of freshly extracted singlerooted teeth $(n=60)$ were instrumented using rotary instruments. The roots were randomly assigned to one of the following experimental groups: (1) a calcium silicate-based sealer without a core material (bulk-fill); (2) a calcium silicate-based sealer + gutta-percha; (3) a calcium silicate-based sealer + Resilon; (4) a methacrylate resin-based sealer (RealSeal SE) + Resilon; (5) an epoxy resin-based sealer (AH Plus) + gutta-percha, and (6) a mineral trioxide aggregate-based endodontic sealer (MTA Fillapex) + gutta-percha. Four 1-mm-thick sections were obtained from the coronal aspect of each root ( $n=40$ slices/group). Push-out bond strength testing was performed at a cross-head speed of $1 \mathrm{~mm} / \mathrm{min}$, and the bond strength data were analyzed statistically by one-way analysis of variance and Tukey tests $(p<0.05)$. The highest and lowest debonding values were obtained for the calcium silicate-based sealer bulk-fill and mineral trioxide aggregate-based endodontic sealer + gutta-percha groups, respectively $(p<0.05)$. It was concluded that the calcium silicate-based sealer showed higher resistance to dislocation in the bulk-filled form than in conjunction with the tested core filling materials. When the calcium silicate-based sealer was placed in bulk, its dislocation resistance was similar to that of commonly used sealer + core root filling systems. Thus, the concept of using a calcium silicatebased sealer in bulk can be more easily advocated in clinical practice.
\end{abstract}

Keywords: Root Canal Obturation; Root Canal Therapy; Dentin.

\section{Introduction}

Three-dimensional obturation of the root canal system is key for successful endodontic therapy., Among a plethora of materials and techniques available today, the use of a sealer in conjunction with a thermoplastic core material has remained the most widely accepted approach for filling the root canals. ${ }^{3}$ Regardless of the filling technique, the use of a sealer is essential $^{4}$ because it establishes a unique joint between radicular dentin and the filling material. ${ }^{5}$ Consequently, an ideal sealer should adhere to both the dentin and the core filling, ${ }^{6}$ hermetically seal the root canal system without being disrupted in the long term, ${ }^{6,7}$ and resist dislocation during tooth 
flexure and operative procedures. ${ }^{5,8}$ No current sealer is capable of providing all of these properties.

Recently, a calcium silicate-based sealer has been introduced, described by the manufacturer as an insoluble, radiopaque, aluminum-free material that requires the presence of water to set and harden (www.ibioceramix.com). The extremely small particle size of this premixed, injectable material enhances its flow into dentinal tubules, lateral canals, and anatomic imperfections, leading to improved adaptation and gap-free seal. ${ }^{9}$ The calcium silicate-based sealer has shown antibacterial effectiveness against Enterococcus faecalis in vitro, ${ }^{10}$ as well as good biocompatibility and increased expression of mineralization-related genes. ${ }^{11}$

The calcium silicate-based sealer is claimed by its manufacturer to perform successfully as a root filling material with or without the use of guttapercha points. In the latter form (i.e., bulk), iRoot SP was recently shown to perform similarly to a epoxy resin-based sealer and significantly better than calcium hydroxide- and methacrylate resin-based sealers in terms of radicular push-out bond strength. ${ }^{12}$ However, no information is available regarding its adhesive strength when used with a core filling material and whether its dislocation resistance in conjunction with a core material is superior to that of its bulk-filled form as well as to that of other root filling systems. Thus, the aim of this study was to evaluate the radicular push-out bond strength of a calcium silicate-based sealer with or without different core filling materials in comparison with commonly used sealer + core filling systems. The null hypothesis tested was that there is no difference in the dislocation resistance between calcium silicatebased sealer bulk-filled canals and those filled with calcium silicate-based sealer + core filling materials or another tested sealer + core filling systems.

\section{Methodology}

\section{Specimen Preparation}

Sixty periodontally involved, freshly extracted single-rooted teeth (from humans aged $18-45$ years), including maxillary incisors and mandibular premolars with straight roots, were used. Tooth crowns were sectioned off below the cemento-enamel junc- tion for adjusting the root length to approximately 15 $\mathrm{mm}$. The root canals were prepared using ProTaper rotary instruments (Dentsply-Maillefer, Ballaigues, Switzerland) up to master apical rotary size F3 (\#30), in conjunction with $2 \mathrm{~mL}$ of $5.25 \% \mathrm{NaOCl}$ irrigation between each file. Prepared root canals were rinsed with $5 \mathrm{~mL}$ of $17 \%$ ethylenediamine tetraacetic acid (Pulpdent Corporation, Watertown, USA), followed by a final rinse with $5 \mathrm{~mL}$ distilled water, and were dried with paper points. Thereafter, the specimens were randomly assigned to one of the six groups (n $=10$ /group) with respect to the root filling system tested: (1) a calcium silicate-based sealer iRoot SP (Innovative BioCreamix Inc., Vancouver, Canada), without a core material; (2) a calcium silicate-based sealer + gutta-percha; (3) a calcium silicate-based sealer + Resilon (Resilon Research LLC, Madison, USA); (4) a methacrylate resin-based sealer (RealSeal SE, SybronEndo, Orange, USA) + Resilon; (5) an epoxy resin-based sealer (AH Plus, Dentsply DeTrey $\mathrm{GmbH}$, Konstanz, Germany) + gutta-percha; and (6) mineral trioxide aggregate (MTA)-based endodontic sealer (MTA Fillapex, Angelus, Londrina, Brazil) + gutta-percha. All materials were applied with strict adherence to the manufacturers' recommendations. Following root filling procedures, the specimens were stored at $37^{\circ} \mathrm{C}$ and $100 \%$ humidity for 1 week to allow complete set of the test materials.

\section{Push-out Bond Strength Test}

Four 1-mm-thick horizontal sections were obtained consecutively from each specimen ( $\mathrm{n}=40$ slices/ group), from the coronal-to-apical direction, using a water-cooled precision saw (Ernst-Leitz, Wetzlar, Germany). Root sections demonstrating the oval root canal form (i.e., non-instrumented areas) were discarded and replaced with a new specimen prepared in accordance with the experimental protocol for that group..$^{13}$ Thereafter, the filling material was loaded using a $0.75-\mathrm{mm}$-diameter stainless steel cylindrical plunger, which provided the most extended coverage over the filling material without coming into contact with the surrounding dentin. Because of the convergence of the root canal sections, the push-out force was applied from the apical to the coronal direction. Loading was performed on a universal testing 
machine, Lloyd LRX (Lloyd Instruments Ltd., Fareham, United Kingdom), at a cross-head speed of 1 $\mathrm{mm} / \mathrm{min}$ until bond failure occurred. The force was recorded using Nexygen data analysis software (Lloyd Instruments Ltd., Fareham, United Kingdom), and the debonding values were used to calculate pushout strength in megapascals (MPa). ${ }^{14}$

\section{Analysis of Failure Modes}

Following the push-out test, the failure modes of each specimen on both surfaces were evaluated under a stereomicroscope (Olympus Optical Co. Ltd., Tokyo, Japan) at 40× magnification and classified into one of the following categories: (I) adhesive (failure at the sealer-dentin interface or sealer-core interface), (II) cohesive (failure within the sealer or dentin), and (III) mixed (failure in both the sealer and dentin). ${ }^{14}$ Two specimens, representative of the failure modes from each group, were evaluated under a scanning electron microscope (JSM 5500; Jeol Ltd. Paris, France). ${ }^{14}$

\section{Statistical Evaluation}

SPSS 15.0 (Statistical Package for Social Sciences, IBM, New York, USA) for Windows 2007 (Microsoft, Albuquerque, USA) was used for statistical analysis of the results. Whether the data were normally distributed was determined using the Shapiro-Wilk test. Homogeneity of variances was evaluated by Levene's test. While evaluating the data using descriptive statistical methods, we evaluated parameters with normal distribution to compare quantitative data using one-way analysis of variance and Tukey post hoc tests with the significance level set at $p<0.05$.

\section{Results}

The push-out bond strength values are presented in Table 1 as mean \pm SD.

The highest and lowest mean push-out values were obtained for the calcium silicate-based bulk-fill sealer (i.e., without core material) and the methacrylate resin-based sealer + Resilon, respectively (both $p<0.05$, Tukey test). A statistically significant ranking for bond strength values was obtained as follows: a calcium silicate-based bulk-fill sealer $\geq$ an epoxy resin-based sealer + gutta-percha $\geq$ a calcium silicatebased sealer + gutta-percha $\geq$ a calcium silicate-based sealer + Resilon $\geq$ mineral trioxide aggregate-based endodontic sealer + gutta-percha $\geq$ a methacrylate resin-based sealer + Resilon $(p<0.05)$.

Table. Push-out bond strength values (MPa, mean \pm standard deviation) of the experimental groups. Within each column, values with different lowercase superscript letters are significantly different at $\mathrm{p}<0.05$ (One-way ANOVA and Tukey tests).

\begin{tabular}{ll}
\hline Root Filling & Bond strength $(\mathrm{MPa})$ \\
\hline iRoot SP without core material & $2.03 \pm 0.49^{\mathrm{a}}$ \\
& \\
iRoot SP + gutta-percha & $1.61 \pm 0.57^{\mathrm{ab}}$ \\
iRoot SP + Resilon & $1.44+0.41^{\mathrm{bc}}$ \\
RealSeal SE + Resilon & $0.94 \pm 0.41^{\mathrm{c}}$ \\
AH Plus + gutta-percha & $1.63 \pm 0.38^{\mathrm{ab}}$ \\
MTA Fillapex + gutta-percha & $1.06 \pm 0.35^{\mathrm{c}}$ \\
\hline
\end{tabular}

The percentage distribution of failure modes is presented in Figure 1, and representative scanning electron microscopy images of the failure modes for each corresponding type of failure can be seen in Figure 2. Adhesive failure at the sealer-dentin interface was the predominant failure mode in the calcium silicate-based sealer bulk-fill group, whereas adhesive failure at the sealer-core interface was the most common type of fracture mode for other test groups.

\section{Discussion}

The bond strength of an endodontic sealer to radicular dentin is essential for maintaining the integrity of the root canal seal ${ }^{5}$ in both the static condition and in resisting displacement of the filling material during function and preparation of post space. ${ }^{8,15}$ In the present study, the push-out test was used because it has become a widely accepted method for recording the interfacial bond strength of endodontic materials to root dentin, even at low levels. ${ }^{16}$ It has been shown that the push-out test produces a more homogenous stress distribution and less variability than the microtensile bond test during dislocation resistance testing to intraradicular dentin. ${ }^{17}$ An additional advantage of using the push-out test is that multiple slices can be obtained from a single root specimen. ${ }^{18}$ On the other hand, most studies evaluating push-out bond strength have used single-rooted human teeth, despite the fact that the structure of root canal dentin is differ- 


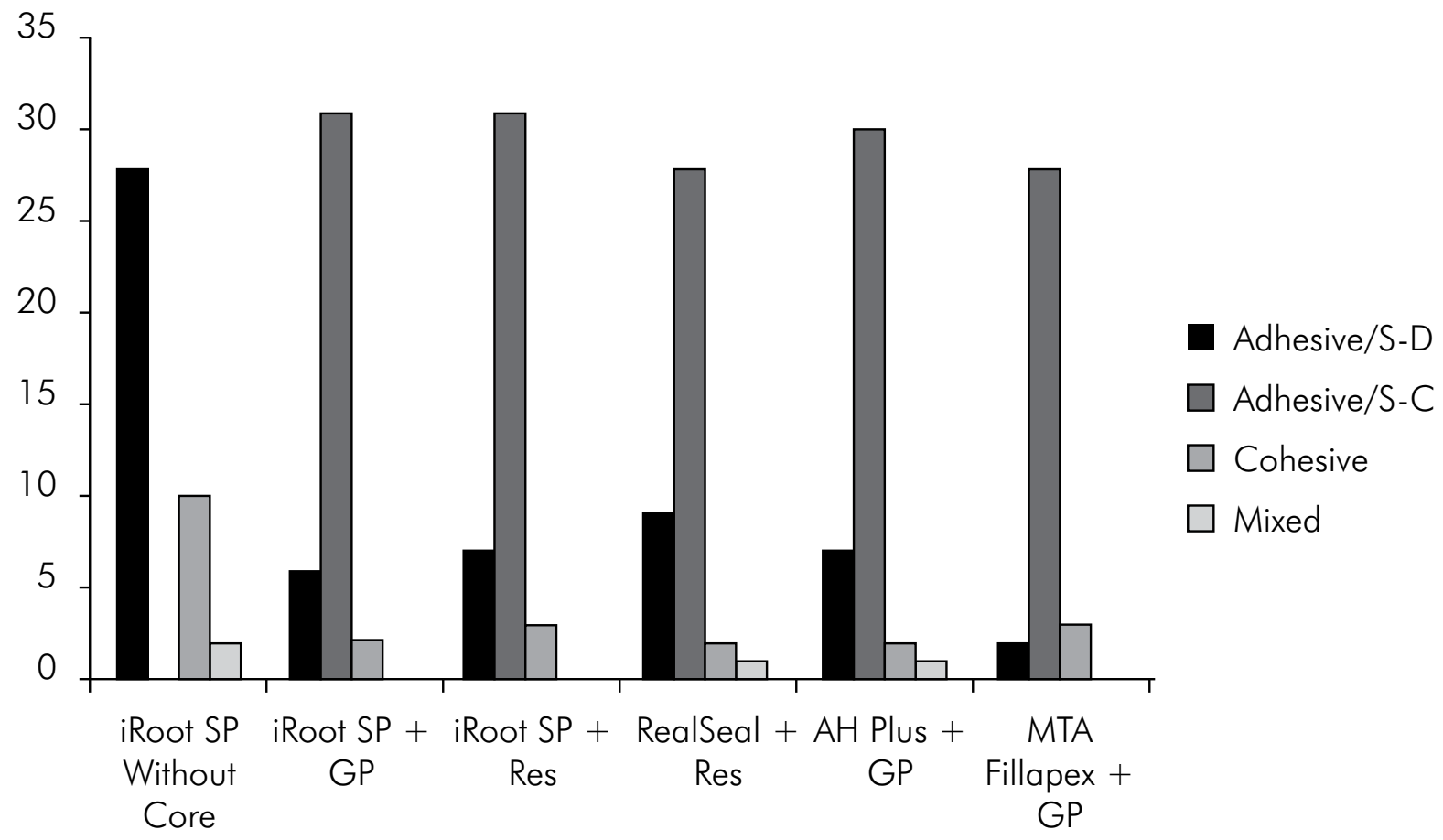

Figure 1. Distribution of failure modes $(G P=$ Gutta-percha, $R E S=$ Resilon, $S-D=$ Between sealer and dentin, $S-C=B$ etween sealer and core material).

ent for each tooth. Although tooth distribution may influence bond strength results, those values might be too low in the clinical scenario.

When tested in bulk, a calcium silicate-based sealer exhibited significantly higher dislocation resistance than its experimental version involving a Resilon main core, as well as the mineral trioxide aggregatebased endodontic sealer + gutta-percha and methacrylate resin-based sealer + Resilon groups. Thus, the null hypothesis should be partially rejected. Compared with the remaining experimental groups (a calcium silicate-based sealer + gutta-percha and an epoxy resin-based sealer + gutta-percha), the pushout strength of the calcium silicate-based sealer bulkfill group was still higher, without significant differences. These results confirm those of previous studies utilizing identical or modified push-out testing conditions, which reported that root canal sealers demonstrate considerably higher bond strength values in the bulk-filled form than in conjunction with a core filling material..$^{5,19}$ More specifically, this might be the case for calcium silicate-based root canal sealers, ${ }^{5}$ regardless of proprietary differences that might exist. The use of iRoot $\mathrm{SP}$ without a core material creates only one interface between the root filling material and root dentin. When used in bulk, the sealer should allow optimal monoblock formation along the root canal walls, leading to more ideal sealer-dentin dislocation resistance, without the limited dislocation resistance between the core material and sealer imposed by the core material. Conversely, when iRoot $\mathrm{SP}$ is used with a main core, the type of obturation should logically lack homogeneity, with spaces found between the master cone and sealer, ${ }^{20}$ which would potentially decrease the quality of the obturation. ${ }^{21}$

Here, the finding that the failures of the calcium silicate-based sealer in conjunction with core materials were adhesive in nature confirms its limited ability (or lack thereof) to adhere to gutta-percha and Resilon, and suggests that a calcium silicate-based sealer bonds much more strongly to dentin than to the tested core filling materials. Although root canals are rarely filled only with sealers in contemporary endodontics, this scenario was tested to reflect the reductions in C-factor that may occur when canals are filled only with sealers. ${ }^{22}$ In addition, it may be 



Figure 2. Scanning electron micrographs depict representative failure modes for each corresponding type of failure. A. Adhesive /S-D, B. Adhesive/ S-C, C. Cohesive, D. Mixed (GP= Gutta-percha, RES=Resilon, S-D = Between sealer and dentin, S-C =Between sealer and core material).

speculated that some inherent properties of the calcium silicate-based sealer-including the calcium silicate composition, which helps minimize shrinking during setting, ${ }^{23}$ and the extremely small particle size and level of viscosity, which enhance flow into dentinal tubules ${ }^{24}$ - may have enhanced its bonding effectiveness to root canal dentin, resulting in increased dislocation resistance.
Although push-out testing of the calcium silicate-based sealer with a Resilon core was solely an experimental approach, the fact that their combination yielded significantly greater dislocation resistance than the combination of the methacrylate resinbased sealer and Resilon merits further investigation, because a calcium-silicate-based sealer cannot adhere to Resilon cones. Presumably, the frictional 
interaction between the calcium silicate-based sealer and Resilon generates higher resistance to debonding than the chemical bond between Resilon and the methacrylate resin-based sealer. As for the difference between the push-out strength of the calciumsilicate-based sealer with Resilon and gutta-percha, it might be logical to assume that not only is guttapercha more compactable than Resilon but also its modulus of elasticity is higher than that of Resilon, which might help resist its dislocation and thus generate greater debonding values. ${ }^{25,26}$

According to the present results, the epoxy resinbased sealer showed significantly higher dislocation resistance than the methacrylate resin- and mineral trioxide aggregate-based sealers, ranking second among the sealers tested. This result corroborates those of previous studies ${ }^{26,27}$ showing that the epoxy resin-based sealer had significantly higher bond strength to radicular dentin than the tested methacrylate resin- and mineral trioxide aggregate-based sealers. The results obtained with the epoxy-resin-

\section{References}

1. Ng YL, Mann V, Rahbaran S, Lewsey J, Gulabivala K. Outcome of primary root canal treatment: systematic review of the literature. Part 2. Influence of clinical factors. Int Endod J. 2008 Jan;41(1):6-31. Epub 2007 Oct 10.

2. Sjogren U, Hagglund B, Sundqvist G, Wing K. Factors affecting the long-term results of endodontic treatment. J Endod. 1990 Oct;16(10):498-504.

3. Ørstavik D. Materials used for root canal obturation: technical, biological and clinical testing. Endod Topics. 2005 Nov;12(1):25-38.

4. Nielsen BA, Beeler WJ, Vy C, Baumgartner JC. Setting times of Resilon and other sealers in aerobic and anaerobic environments. J Endod. 2006 Feb;32(2):130-2

5. Huffman BP, Mai S, Pinna L, Weller RN, Primus CM, Gutmann JL, et al. Dislocation resistance of ProRoot Endo Sealer, a calcium silicate-based root canal sealer, from radicular dentine. Int Endod J. 2009 Jan;42(1):34-46.

6. Shipper G, Ørstavik D, Teixeira FB, Trope M. An evaluation of microbial leakage in roots filled with a thermoplastic synthetic polymer-based root canal filling material (Resilon). J Endod. 2004 May;30(5):342-7.

7. Ureyen Kaya B, Keçeci AD, Orhan H, Belli S. Micropush-out strengths of gutta-percha versus thermoplastic synthetic poly-mer-based systems-an ex vivo study. Int Endod J. 2008 Mar;41(3):211-8. based sealer may be associated with its low shrinkage during the setting phase, as well as its long-term dimensional stability. ${ }^{28,29}$

While it is evident that the bond strength values obtained herein are too low in terms of root reinforcement, endodontic materials with low bond strength to dentin should still be considered good if they are effective in preventing microleakage. ${ }^{30}$ Thus, provided that the sealing efficiency of a calcium silicate-based sealer without a main core is shown to be superior to those of the current sealer + core root filling systems, the concept of using a calcium silicate-based sealer in bulk can be more easily advocated in clinical practice.

\section{Conclusion}

Within the experimental conditions of the present study, it can be concluded that a calcium silicate-based sealer without a core material exhibited the greatest resistance to dislocation from radicular dentin, and the lowest mean push-out values were obtained for the methacrylate resin-based sealer with a Resilon core material.

8. Panitvisai P, Messer HH. Cuspal deflection in molars in relation to endodontic and restorative procedures. J Endod. 1995 Feb;21(2):57-61.

9. Zhang W, Li Z, Peng B. Assessment of a new root canal sealer's apical sealing ability. Oral Surg Oral Med Oral Pathol Oral Radiol Endod. 2009 Jun;107(6):e79-82.

10. Zhang H, Shen Y, Ruse ND, Haapasalo M. Antibacterial activity of endodontic sealers by modified direct contact test against Enterococcus faecalis. J Endod. 2009 Jul;35(7):1051-5.

11. Zhang W, Li Z, Peng B. Effects of iRoot SP on mineralization-related genes expression in MG63 cells. J Endod. 2010 Dec;36(12):1978-82.

12. Ersahan S, Aydin C. Dislocation resistance of iRoot SP, a calcium silicate-based sealer, from radicular dentine. J Endod. 2010 Dec;36(12):2000-2.

13. Peters OA. Current challenges and concepts in the preparation of root canal systems: a review. J Endod. 2004 Aug;30(8):559-67.

14. Skidmore LJ, Berzins DW, Bahcall JK. An in vitro comparison of the intraradicular dentin bond strength of Resilon and gutta-percha. J Endod. 2006 Oct;32(10):963-6.

15. Tagger M, Tagger E, Tjan AHL, Bakland LK. Measurement of adhesion of endodontic sealers to dentin. J Endod. 2002 May;28(5):351-4. 
16. Goracci C, Tavares AU, Fabianelli A, Monticelli F, Raffaelli O, Cardoso PC, et al. The adhesion between fiber posts and root canal walls: comparison between microtensile and push-out bond strength measurements. Eur J Oral Sci. 2004 Aug;112(4):353-61.

17. Soares CJ, Santana FR, Castro CG, Santos-Filho PC, Soares PV, Qian F, et al. Finite element analysis and bond strength of a glass post to intraradicular dentin: comparison between microtensile and push-out tests. Dent Mater. 2008 Oct;24(10):1405-11.

18. Sadek FT, Monticelli F, Goracci C, Tay FR, Cardoso PE, Ferrari $\mathrm{M}$. Bond strength performance of different resin composites used as core materials around fiber posts. Dent Mater. 2007 Jan;23(1):95-9.

19. Jainaen A, Palamara JE, Messer HH. Push-out bond strengths of the dentine-sealer interface with and without a main cone. Int Endod J. 2007 Nov;40(11):882-90.

20. Gilbert SD, Witherspoon DE, Berry CW. Coronal leakage following three obturation techniques. Int Endod J. 2001 Jun;34(4):293-9.

21. Peters DD. Two-year in vitro solubility evaluation of four gutta-percha sealer obturation techniques. J Endod. 1986 Apr;12(4):139-45.

22. Tay FR, Loushine RJ, Lambrechts P, Weller RN, Pashley DH. Geometric factors affecting dentin bonding in root canals: a theoretical modeling approach. J Endod. 2005 Aug;31(8):584-9.
23. Zhang W, Li Z, Peng B. Assessment of a new root canal sealer's apical sealing ability. Oral Surg Oral Med Oral Pathol Oral Radiol Endod. 2009 Jun;107(6):e79-82.

24. Shokouhinejad N, Gorjestani H, Nasseh AA, Hoseini A, Mohammadi M, Shamshiri AR. Push-out bond strength of gutta-percha with a new bioceramic sealer in the presence or absence of smear layer. Aust Endod J. 2013 Dec;39(\#):1002-6. doi:10.1111/j.1747-4477.2011.00310.x

25. Ungor M, Onay EO, Orucoglu H. Push-out bond strengths: the Epiphany-Resilon endodontic obturation system compared with different pairings of Epiphany, Resilon, AH Plus and gutta-percha. Int Endod J. 2006 Aug;39(8):643-7.

26. Nagas E, Uyanik MO, Eymirli A, Cehreli ZC, Vallittu PK, Lassila LV, et al. Dentin moisture conditions affect the adhesion of root canal sealers. J Endod. 2012 Feb;38(2):240-4.

27. Guiotti FA, Kuga MC, Duarte MA, Sant'anna A Júnior, Faria G. Effect of calcium hydroxide dressing on push-out bond strength of endodontic sealers to root canal dentin. Braz Oral Res. 2014 Jan-Feb;28(1). doi: 10.1590/S1806-83242014.50000002.

28. Pommel L, About I, Pashley D, Camps J. Apical leakage of four endodontic sealers. J Endod. 2003 Mar;29(3):208-10.

29. Schafer E, Zandbiglari T. Solubility of root-canal sealers in water and artificial saliva. Int Endod J. 2003 Oct;36(10):660-9.

30. Schwartz RS. Adhesive dentistry and endodontics. Part 2: bonding in the root canal system-the promise and the problems: a review. J Endod. 2006;32(12):1125-34. 